\title{
Framing the constructive alignment of design within technology subjects in general education
}

\author{
Jeffrey Buckley ${ }^{1,2} \cdot$ Niall Seery $^{2} \cdot$ Lena Gumaelius $^{1} \cdot$ Donal Canty $^{3} \cdot$ Andrew Doyle $^{1}$. \\ Arnold Pears ${ }^{1}$
}

Accepted: 16 April 2020 / Published online: 27 May 2020

(c) The Author(s) 2020

\begin{abstract}
Design is core element of general technology education internationally. While there is a degree of contention with regards to its treatment, there is general consensus that the inclusion of design in some form is important, if not characteristic, of the subject area. Acknowledging that design is important, there are many questions which need to be considered in order to guide policy and practice, such as whether a singular general design ability can be explicitly defined empirically beyond an implicit verbal definition, and whether it can be taught and assessed. In order to address these questions in a systematic fashion, a framework is needed in order to guide relevant investigations. Having such a framework would allow for theory to be generated, hypotheses to be tested, and assumptions to be challenged. In response to this apparent need, this article presents a theoretical discussion pertaining to the constructive alignment of learning to design, wherein theories of knowledge, variation theory, knowledge transfer, and assessment validity and reliability are reflected upon.
\end{abstract}

Keywords Design · Constructive alignment · Technology education · General education · Theory generation

Technology related subjects exist in a variety of formats internationally within secondary, general education, curricula. For example, in Ireland a suite of four subjects are considered as technology subjects at lower secondary education; Wood Technology, Engineering, Applied Technology, and Graphics (NCCA 2018a, b, c, 2019), with a further four at upper secondary education; Construction Studies, Engineering, Technology, and Design and Communication Graphics (NCCA 1983, 1984, 2007a, b). In the Swedish compulsory school system there exists the subject of Technology and two subjects with similarities to aspects of technology education internationally; Crafts (Slojd) and Home and Consumer

Jeffrey Buckley

jbuckley@kth.se

1 KTH Royal Institute of Technology, Stockholm, Sweden

2 Athlone Institute of Technology, Westmeath, Ireland

3 University of Limerick, Limerick, Ireland 
Studies (Hem och Konsumentkunskap) (Skolverket 2018). In England, the subject of Design and Technology (D\&T) exists at Key Stages 1, 2, and 3 of secondary education (DfE 2013a, b). In the South African General Education and Training (GET) band, technology education can be seen in the subject of Natural Sciences and Technology in Grades 4-6 and as Technology in Grades 7-9 (DBE 2013). Finally, in the Maltese primary curriculum (Years 1-6) there is a technology education programme, in middle school (Years 7-8) there is a subject called Design and Technology, and in secondary school (Years 9-11) there is a subject called Design and Technology as well as subjects called Graphical Communication, Science and Technology, and Textiles Studies which could be considered as technology subjects depending on the adopted philosophical position (Government of Malta 2015). Presenting the format of technology education in these countries serves only to indicate the existence of multiple formats internationally and there is a myriad of examples which could be used to exemplify differences in how technology education is enacted in secondary education globally. The existence of this variance however provokes the need to consider, as each of these subjects purport to reflect technological education in some way, is there a commonality which can aid in making the remit of technology education more explicit? At the intersection of all (or some) of these curricula does there exist a common characteristic which differentiates technology education from other subject areas within general education? In other words, what do secondary education students gain from participating in technology subjects that they do not gain from other subjects, or, what is the unique contribution to national curricula from technology education?

Within each country that offers a form of technology education at second level, curricula contain learning outcomes associated with knowledge and skills, and perhaps also values, attitudes, and dispositions, which are deemed to be contextually relevant based on local societies and cultures. As there is a focus on technology in one or multiple conceptualisations (e.g., as objects, as knowledge, as actions, or as volition: Mitcham 1994), there is an ever-growing body of information reflecting technological advances which can be considered within these subjects. Naturally, there will be variance in the learning outcomes between countries, and within countries where multiple technology related subjects exist. However, there does appear to be a commonality in the inclusion of design, at least philosophically, which has garnered a degree of consensus (Ankiewicz and De Swardt 2006; Barlex 2007; Barlex and Trebell 2008; Cropley and Cropley 2010; Jones et al. 2013; Kimbell 2011; Kimbell and Stables 2007; Norman and Baynes 2017; Pool et al. 2013; Rossouw et al. 2011; Seery et al. 2012; Williams 2009). This is not to suggest that there is agreement on the treatment of design, but teaching to and/or through design appears central within the pertinent discourse (Hallström and Ankiewicz 2019). There is also discussion centring on the emphasis that should be placed on design. For example, in the UK there are calls to reform secondary education D\&T education to place greater emphasis on design in the form of design thinking (Spendlove 2017) as well as reflections that there should be less of an emphasis placed on design and that greater emphasis should be placed on technology (Barlex 2019). While the inclusion of design arguably merits celebration (as evidenced by the advocacy for it within pertinent discourse), it is also a critical element to the delegitimisation narrative facing technology related subjects in many countries (Seery et al. 2019). Design induces a natural variance in practice (Atkinson 2017), is difficult to assess (Seery et al. 2012), and evokes questions regarding its 'learnability' and 'teachability' as a result of being an innately human activity (Geary 2007, 2008; Seery 2017; Stables 2008). A further fundamental problem of explicability is exemplified by Newman (2017, p. 28) when he says "I know what I know as a designer. I know how to explain what I know to other designers. Explaining how I know what I know to a non-design audience is harder to 
explain". A direct result of this difficulty in making design explicit is an inherent degree of trust associated with its inclusion in general education. This is compounded further due to the complexity associated with design as an educational activity, the many tacit aspects of it, and as the evidence base is not conclusive in terms of how design is to be enacted and the associated benefits. Additionally, as the majority of stakeholders who aren't educators tend to be a 'non-design audience' a sense of risk can be created with design related learning outcomes. Design, therefore, when considered within second level technology subjects which are a part of a general education curricula, warrants problematizing and framing to consider and address questions such as; what elements of designerly ability can and cannot be learned? What elements can and cannot be taught? How are the learnable and teachable elements best learned and taught? Can such elements be validly and reliably assessed and if so how? How can and should design be incorporated into technology education as a pedagogical activity? And, how does design fit within existing empirically supported theories of teaching and learning (Seery et al. 2019)? In an agenda to address these questions empirically, there is a need for studies to be able to frame exactly how design is being considered in order to make inferences relative to generalisability.

Critically, design can be considered in two forms within education, i.e. learning to and/ or through design. It is reasonable to consider them in tandem, for example learning to design by learning through design, however outside of this case, it is perhaps clearer to differentiate both treatments of design. Learning through design is essentially a discussion concerning pedagogical selection, with such discussion being significantly impacted by the intended object of learning. As there is substantial literature associated with pedagogical selection (e.g. Hmelo-Silver et al. 2007; Kirschner et al. 2006; Kuhn 2007; Schmidt et al. 2007; Sweller et al. 2007) this article focusses predominantly on learning to design, with minor discussion on learning through design due to the natural overlap. Importantly, this article also does not intend to offer an explicit verbal definition for design. As discussed in a later section, design may be best conceptualised as singular or manifold. Instead, this article focusses on a conceptual idea of a general design ability, in other words, some singular general capacity that affords people to design better regardless of the design activity and context. This is perhaps best considered relative to the implicit theory described by Stables (2008) wherein the three human abilities of being able to image in our minds, manipulate those images, and to externally utilise those images to enact future change contribute to human designerly ability. Where these abilities could be viewed as factors of a design ability, a single unifying design ability could be viewed as an underlying commonality which enables humans to engage in these activities.

While there has been considerable evolution of design within technology education research, it is argued that the lack of a theoretical framework, grounded in cognitive psychology due to the focus on the process of learning, impedes further strategic empirical progress. It is only on the foundation of such a framework can design be critically considered in practice in a systematic fashion, and through the presentation of such a framework that meaningful interrelated hypotheses can be tested to empirically rationalise design as an educational activity within general secondary education. This article therefore discusses learning to design within the framework of constructive alignment (Biggs 1996) wherein design is considered in light of existing empirical evidence and existing pertinent theories of teaching and learning. Naturally, this discussion will not be exhaustive and should be thought of as a work in progress which should be reflected upon in light of new evidence as it emerges, and current evidence which is not reflected within this article. In considering the constructive alignment (Biggs 1996) of learning to design, theories of knowledge will be synthesised with respect to design related 
learning outcomes. It is critical for the progression of design research and enacted practice that what is meant by learning to design is clarified. This may not achieve consensus, but from a research perspective being able to define this within individual studies will allow for work with similar conceptions to be synthesised without confusion of conflicting ideologies, and from a practice perspective it could aid in focusing the variation in student experiences. Variation theory and knowledge transfer will be considered as foundational to teaching and learning activities to reflect the nature of enacted practices where design is engaged with in many contexts, for example based on material type (e.g., wood, metal, plastic, food, textiles etc.), outcome (e.g., design with or without make), or audience (e.g., design for elderly people, animals, etc.). Finally, assessment of design will be considered in terms of reliability and validity. An overview of how the constructive alignment of learning to design is being considered in this article is presented in Fig. 1. As the following sections centre on the constructive alignment of learning to design, it is important that they are considered holistically despite being articulated individually, and therefore the discussion section provides a space for synthesis and consideration of falsifiability and empirical progression.

\section{Learning outcomes: theories of knowledge}

As discussed, design related learning outcomes need to be considered from two perspectives; (1) are they associated with learning to design, or (2) are they other technology syllabi specific learning outcomes where design has been selected as the medium through which they will be attained. Due to how design is considered in both cases, both sets of learning outcomes provoke different theoretical questions, e.g. can a general design ability be learned and/or taught and is design a suitable pedagogical medium, and therefore require separate treatment. In considering learning outcomes associated with learning to design, theories of knowledge associated with biologically primary and secondary knowledge, explicit and tacit knowledge, and technological knowledge will be reflected upon in the following sections.

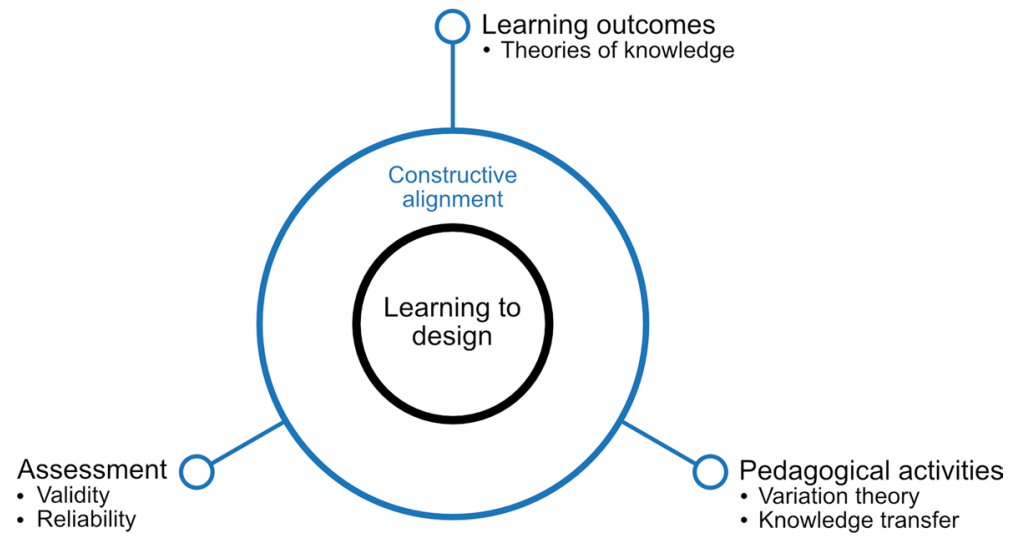

Fig. 1 Considerations within the constructive alignment of learning to design 


\section{Biologically primary and biologically secondary knowledge}

Geary's division of biologically primary and biologically secondary knowledge (Geary $1995,2007,2008$ ) was a significant advancement for education, particularly in relation to instructional design. Biologically secondary knowledge is learnable and teachable whereas biologically primary knowledge is learnable but not teachable. Humans have evolved to assimilate biologically primary knowledge through immersion, with examples being learning to listen and speak a first language. No formal curricula is needed to acquire this knowledge, all that is necessary is membership in a functioning society (Sweller et al. 2011). In contrast, biologically secondary knowledge, the knowledge for which educational institutions were invented (Sweller 2008), requires explicit instruction to be taught effectively. Herein lies arguably the most important consideration for learning outcomes associated with design in general education; the existence or lack of existence of a consistent context. Design is fundamentally problem solving, and general problem solving, such as means-end analysis (e.g. Newell and Simon 1972; Sweller 1988), as well as decision making and thinking, are biologically primary activities (Sweller et al. 2011). However, when a consistent context is added, for example in engineering design, structural design, software design, design with specific materials or processes etc. design is better considered as a biologically secondary activity as teachable design skills, knowledge and heuristics exist which are transferable at least within the immediate context and perhaps to other contexts. The idea of a consistent context for design will be a reoccurring theme, as without this, it is questionable whether design is teachable. This is exemplified by Seery (2017) through his reflection of a child designing a solution to gain additional height to gain access to a sweet jar. If design in schools cannot clearly illustrate learning (associated with being able to design) beyond the biologically primary activity reflective of a child conceiving, implementing and evaluating a solution, there is an issue with the conceptual framing of the design activity.

\section{Tacit and explicit knowledge}

Building on the constructs of biologically primary and secondary knowledge, the explicability of the knowledge associated with learning outcomes necessitates consideration. Reflecting on the previous quote by Newman (2017), there is a need to consider the tacit and explicit nature of knowledge (Collins 2010; Polanyi 1969). In considering knowledge in this way, it is critical to be clear on the differentiation between these types of knowledge as there is contention associated with the definition of tacit knowledge. Tacit knowledge is often defined as knowledge which is not yet explicated (Collins 2010; Spender 1993) which presents an ambiguity as to whether this is a result of a person's lack of capacity with natural language, i.e. the person with the knowledge is unable to explicate it at a moment in time but may be able to do so in the future, or if it is because of an inherent quality of the knowledge itself making it inexplicable. Collin's (2010) clarifies this by noting Polanyi's (1969) use of the term to mean knowledge which inherently cannot be explicated, making it differentiable from explicit knowledge which can be. Considering Newman's (2017) statement that it is more difficult (with no implication or qualification that it is impossible) to describe what he as a designer knows to a non-designer, suggests merit in reflecting on the explicability of general design skills as learning outcomes. It is widely agreed upon that learning outcomes should be explicit where possible (e.g. Lawlor and Hornyak 2012) for a 
variety of reasons such as fairness, transparency, quality assurance, assessment validity and the alignment of pedagogy. Therefore, learning outcomes associated with general design knowledge and skills should be explicable where possible, albeit considerate of the tacit nature of aspects related to design, but this should be considered as a function of the expertise of the learner, which will be considered in more detail in a subsequent section with respect to the context of design.

\section{Technological knowledge}

Learning outcomes in technology education take various forms, however they are most often discussed broadly with respect to technological capability (Buckley et al. 2019; Gibson 2008; Rauscher 2011; Shaw 2002) and technological literacy (Dakers 2006; Ingerman and Collier-Reed 2011; Williams 2009). These are not considered internationally to be the aims exclusively, for example the Scottish curriculum has made reference to the aspects of technological perspective, technological confidence, technological sensitivity, and technological creativity (Scottish CCC 1996), but they are the most prominent within the discourse. In fact, it could be argued that the discourse has evolved to the point where the terms literacy and capability are no longer adequate descriptors. However, the concept of technological capability has been deliberated in terms of knowledge in a way which can contribute to the conceptualisation of design. Buckley et al. (2019), through consideration of other knowledge taxonomies and theories of knowledge (Alavi and Leidner 2001; Anderson 1983; Gibson 2008; Gorman 2002; Huang and Yang 2009; McCormick 1997; Pirttimaa et al. 2017; Ryle 1949), view technological capability as a synthesis of declarative, conceptual, procedural, conditional and causal knowledge. A differentiating characteristic between declarative, conceptual, and procedural knowledge with conditional and causal knowledge is that the latter describe some inherent form of judgement whereas the former do not, which could be thought of as a difference between training (no necessary judgement in the knowledge required for enactment) and education (necessary judgement or decision making). Design related learning outcomes could be considered in a similar light as a subset of technological learning outcomes, as there may be design related knowledge and skills which are declarative and procedural, and there may be others which are conditional and causal. Declarative and procedural learning outcomes perhaps do not all require a consistent context, however it is arguable that conditional and causal learning outcomes do.

\section{Teaching and learning activities: variation theory and knowledge transfer}

If the learning aim is to develop designerly competencies, there must be an assumption that this refers to developing biologically secondary knowledge. While designing is an innately human activity (Stables 2008), its inclusion within formal curricula suggests it is something that can be taught. Professional designers exist within consistent contexts, such as interior designers, industrial designers, and fashion designers. These people have an in-depth knowledge and understanding of their domain from the staple materials they work with to the common practices and heuristics which have utility in their design processes. These examples offer evidence that design skills can be developed within a context, and through the considering of variation theory and knowledge transfer it is argued that 
learning to design within general education should adopt a similar model, i.e., learning to design within a consistent context, but including variation within that particular context to allow for commonality to be observed.

\section{Variation theory}

Variation theory stems from phenomenographic research (Runesson 2005) and "is a theory of learning and experience that explains how a learner might come to see, understand, or experience a given phenomenon in a certain way" (Orgill 2012, p. 3391). The focus on the object of learning is a significant feature of variation theory (Runesson 2006) and in this case, the object of learning would be design or design knowledge and/or skills. Therefore, from the perspective of variation theory, where learning is defined "as a change in the way something in seen, experienced or understood" (Runesson 2005, p. 70), learning to design would see students come to either see, experience or understand design, or perhaps more specifically a design related piece of knowledge or skill, in a new way.

Bussey et al. (2013, p. 10) note that "to better understand what something is, it is often equally as important to understand and contrast it with what it is not". Thus, in order to discern some aspect of a phenomenon, an individual must experience variation in that aspect. In this sense, should students engage in a series of design tasks with differing contexts, objects of learning associated with learning to design could be inferred to be context specific. Alternatively, where objects of learning are context specific, variation of context could result in students being unable to identify the consistency of the object of learning and thus may not assign it significant enough value to attend to as a learning objective.

The experience of variation allows the learner to create meaning for the phenomenon. Variation then is considered as a necessary condition for learning to design (Runesson 2006), however what this variation would be is important to consider. To identify this, it is necessary to acknowledge the four significant patterns of variation (Marton and Tsui 2004). These include (Bussey et al. 2013, pp. 14-15):

- Contrast which allows the individual to compare an object of learning or a feature of that object with something it is not.

- Generalisation which allows the individual to compare similar instances of the object of learning.

- Separation which allows the individual to discern one feature of an object of learning from other features by varying only the feature of interest while holding all other features constant.

- Fusion which allows the individual to discern variation in several features of an object of learning simultaneously.

Considering design within a context, where that context is defined as some form of constant such as a domain, artefact, or material, allows learners to learn particular processes or considerations which result in either a better process of designing or a better design outcome. Similarly, by maintaining a common context in this way, there will be some similarity in the outcome, allowing for a better construct of capability to be developed, which in turn creates a feedback loop for the learner aiding in their development. Without a common context, the capacity for a learner to experience a pattern of variation is reduced, i.e. the common context allows for variation to be strategically and pedagogically introduced, and 
therefore while learning may occur without a common context, there is a lower likelihood that it will be as meaningful to the learner or as efficient.

\section{Knowledge transfer}

Similar to learning through variation, the transferability (Ormrod 2014) of objects of learning is a key consideration as learning does not only mean that knowledge and skills can be reproduced in situations which have been previously experienced, but that they can be applied in novel situations (De Corte 2003; Goldwater and Schalk 2016). Each of the types of transfer described by Ormrod (2014) should be acknowledged relative to design related learning outcomes and therefore to aid in their consideration they are described below (Ormrod 2014, pp. 385-386):

- Positive transfer describes when "learning in one situation facilitates learning or performance in another situation".

- Negative transfer describes when "something learned in one situation hinders a person's ability to learn or perform in a second situation".

- Vertical transfer describes when "a learner acquires new knowledge or skills by building on more basic information and procedures".

- Lateral transfer describes when "knowledge of the first topic is helpful but not essential to learning the second one".

- Near transfer involves "situations or problems that are similar in both superficial characteristics and underlying relationships".

- Far transfer involves "two situations that are similar in one or more underlying relationships but different in their surface features".

- Specific transfer describes situations whereby "the original learning task and the transfer task overlap in some way".

- General transfer describes situations whereby "the original task and the transfer task are different in both content and structure".

If, momentarily, the concept of knowledge is viewed holistically to mean an object of learning, transferability invokes the need to consider the ideas of knowledge of the problem and knowledge for the solution (Barlex and Steeg 2017). Knowledge of the problem "is always specific to the problem being addressed and needs to be found by exploring the situation in which the problem is embedded" (Barlex and Steeg 2017, p. 16) whereas knowledge for the solution "can be more easily recognised and acquired than knowledge of the problem in that, from any domain of design and technology, the knowledge does not change as the design task changes" (Barlex and Steeg 2017, p. 17). If a domain of technology education relative to design remains consistent, learning to and through design can become easier as there is an increased commonality and thus transferability in the knowledge usable for the solution. If, for example, there is consistency in the use of materials, due to the continued experience of working with a particular material students have an increased opportunity to acquire such skills as knowledge for the solution despite potentially stark changes in knowledge of the problem. Similarly, if the context is not a material but a field, such as fashion or interior design, while knowledge of the problem, e.g. of the client, may change significantly, knowledge for the solution in terms of pertinent field specific design heuristics may remain consistent thus providing more opportunity for learning. If there is too much variation in the context of the design, such that far transfer of 
knowledge is difficult or irrelevant, then it is questionable if meaningful learning can occur, or at least be seen, as prior knowledge may not be drawn upon. For example, if the field that successive design tasks are situated within changes, such as from having an industrial context to having an environmental context, the design process may vary substantially to the point that there is no transferability in any form. This further evokes the question as to whether there is indeed general design knowledge, skills or heuristics which can induce general transfer across such contexts and which are learnable and teachable, which further call into question the assessability of such.

\section{Assessment: reliability and validity in assessing design}

Assessing design is complex, there are numerous factors which need to be considered, and there has been considerable research done in this area. This article will be restricted to a brief discussion on reliability and validity. Notably, especially with respect to validity, in order to have such discourse there is often a need to assume validity in the associated learning outcomes and task design. For example, there is evidence to suggest that certain demographics of students can be advantaged or disadvantaged as a result of the context of a design task, i.e. the context effect (Kimbell et al. 2004), and therefore even with theoretically valid assessment architectures, the assessment data may be inherently biased. As such, the discussion here associated with validity will focus instead on the capacity to validity assess a construct such as general design ability.

\section{Reliability}

Assessing designerly outputs reliably is an area of research which has seen considerable advances, perhaps even more so than most other areas of design research, through the invention of methodologies of comparative judgement. Comparative judgement, and variations such as adaptive comparative judgement, can essentially mitigate the issues which stem from criterion referenced assessment, namely the sum of criterion scores not reflecting professional holistic assessments, and rubrics being unable to capture the nuances of student work (Sadler 2009). Comparative judgement builds on numerous principles such as Thurstone's (1927) law of comparative judgement and the wisdom of crowds (Surowiecki 2004) and involves 'judges' making binary decisions of holistic quality when comparing two pieces of work rather than comparing a single piece of work against a pre-determined rubric. There is considerable evidence illustrating that high reliability can be achieved using this method both with respect to design related student outputs (Bartholomew et al. 2018a, b, c; Bartholomew and Yoshikawa-Ruesch 2018; Canty et al. 2012; Kimbell 2012; Seery et al. 2012, 2019; Williams and Kimbell 2012) and to outputs from other subject areas (Jones et al. 2015; Jones and Alcock 2014; Steedle and Ferrara 2016). Due to this evidence, research has evolved from considering comparative judgement as a tool to aid in reliable assessment to examining it from a logistical perspective (Steedle and Ferrara 2016).

\section{Validity}

When considering the validity of assessment for design tasks, there are certain issues which exist that are generalisable to assessment in the majority of instances, such as face validity, 
content validity, and external validity. However, Newman's (2017) previous quote raises a dilemma for the assessment of design in that it can be difficult for a non-design audience to see or comprehend the nuances associated with designerly outputs. In research involving the use of adaptive comparative judgement, studies have involved the students as assessors (Canty et al. 2012; Seery et al. 2012) as despite being novices, they were able to achieve consensus in their judgements "on the basis of the epistemological understanding developed by each individual student as a result of their engagement in the design task" (Canty et al. 2012, p. 122). In this sense, it is acknowledged that external stakeholders don't have the necessary understanding of the specific task to validly interpret the work, and even though they may garner consensus amongst themselves they may overlook nuances which are only appreciable by the students themselves.

Within a consistent context there is specific knowledge which is transferable at least within that particular context. However, in the presence of varying contexts which could exist in progressive design tasks in general education, where knowledge is less or possibly not transferable, and/or if there is an agenda to develop a general design ability, it is questionable if assessment instruments could align with general design knowledge and skills. Students will develop knowledge and skills associated with specific types of outputs and will, over-time, produce more sophisticated outputs. For example, better craft skill will result in more well-crafted artefacts and better sketching skills could result in better presented outputs associated with ideation. This can certainly result in improved products which result from a design activity, but in terms of validity this needs to be explored in relation to the process of design. Furthermore, this introduces additional variables which may make it difficult for assessors to differentiate the craft skill from the design ability, and presents the question as to whether the assessment is of design, craft skills, or some combination of both. Where this becomes a significant educational implication is in advocating for students and their learning. If there is a general design ability, in terms or knowledge and/or skills, and it cannot be differentiated from craft skills in an assessment context, in terms of student performance it may be more appropriate to teach and/or assess the craft skills independently as that may be the unintended focus of the assessment. This is not to suggest that a synthesis of craft and design is never appropriate, but if assessors are unable to distinguish good design from good craft (in cases where they are separable) then formative feedback from a task intended to support the students in learning to design may be confounded.

\section{Discussion}

In attempting to theoretically frame the constructive alignment of a general design ability which is pertinent to general secondary education curricula, this article essentially proposes two questions; (1) is there such a construct as a general design ability which is teachable, learnable and measureable (validly and reliably) or does design necessitate a consistent context for development to be meaningfully possible, and (2) if there is a general design ability, what transferability does it have such that its development positively (or potentially negatively) impacts on learners across contexts. The agenda of considering design in this is also twofold in that it is hoped it will prompt further rigorous investigations into the nature of design as a learning activity and a learning aim, which will then ultimately improve the knowledge base which educators can draw upon to deliver more effective learning experiences to students. In order to progress this agenda, the essence of the discussion is arguably 
captured in the context of expertise, i.e. how can learners become better, or more expert, designers within technology education, and if design is to be investigated, how can some of the claims and speculations made in this article be falsified. This will be briefly discussed as a means of offering a degree of synthesis of the previously discussion elements of the constructive alignment of design, and also to provoke thought with regards to future research endeavours.

Although the validity of assessment was considered last, it is a crucial element of design research as the determination of the efficacy of a general design ability is predicated on the capacity to validly and reliably measure it as a construct. Therefore, in order to explore many hypotheses and research questions relating to design in general education, there are many precursor questions which require exploration such as who is best position to judge, measure or assess designerly processes and outputs. Additionally, if students are involved as judges, while they may have the greatest level of appreciation and empathy for outputs, their levels of expertise need to be a consideration in terms of the utility of their judgements. Further to this, a general design ability may or may not be best conceptualised as a singular construct. It may be better considered to be manifold and constitute the common variance amongst a series of factors. If this is the case, there are then questions which require consideration such as the breadth of variables requiring acknowledgment in a measurement context, i.e. is it necessary to account for a wide array of variables in a research study or educational assessment, or does one describe a general design ability sufficiently to be used as a proxy even if there will be some degree of error involved.

Assuming a mechanism to assess general design ability exists, there are a wide variety of further hypotheses which can be explored, wherein their acceptance or rejection would add greatly to the present discussion. Drawing on literature associated with expertise, the circumvention-of-limits hypothesis (Hambrick et al. 2012; Salthouse 1991) "is an appealing idea (see Ericsson and Pool 2016) with far reaching implications for the question of what people can achieve through training" (Hambrick et al. 2018, p. 320) and provides an auspicious hypothesis in which design can be considered an analogous variable. The circumvention-of-limits hypothesis holds that "the effect of domain general abilities and capacities on performance diminishes as skill in a task is acquired through training" (Hambrick et al. 2018, p. 307) and stems from classic theories of skill acquisition (Fitts and Posner 1967). While it is typically considered with respect to general cognitive ability, substituting this for a general design ability provides a wealth of research from which to draw upon when investigating design in terms of conceptual and philosophical debate, empirical evidence, and methodological approaches. For example, considering the previous discussion on the context of design and the potential conflation of knowledge and skills with a general design ability, the circumvention-of-limits hypothesis has a major strength in its focus on prior knowledge. Goldwater and Schalk (2016) exemplify why this is so critical by emphasising the importance of prior knowledge, noting that:

Prior knowledge has been shown to greatly affect how learners interpret and learn from their class materials (e.g., Rittle-Johnson et al. 2009), how well they can implement domain-general problem-solving strategies (see, e.g., Koedinger and Roll 2012; Zimmerman 2000, for reviews), how well they are able to generalize knowledge encoded from earning materials to novel cases or problems (e.g., Carpenter et al. 2006) and how well they are prepared for future learning tasks (e.g., Bransford and Schwartz 1999). Further, the degree with which new concepts conflict with the students' prior knowledge (e.g., their naïve theories) is one of the primary determinants of how difficult a concept is to learn (Chi et al. 2012; Jacobson et al. 2011). 

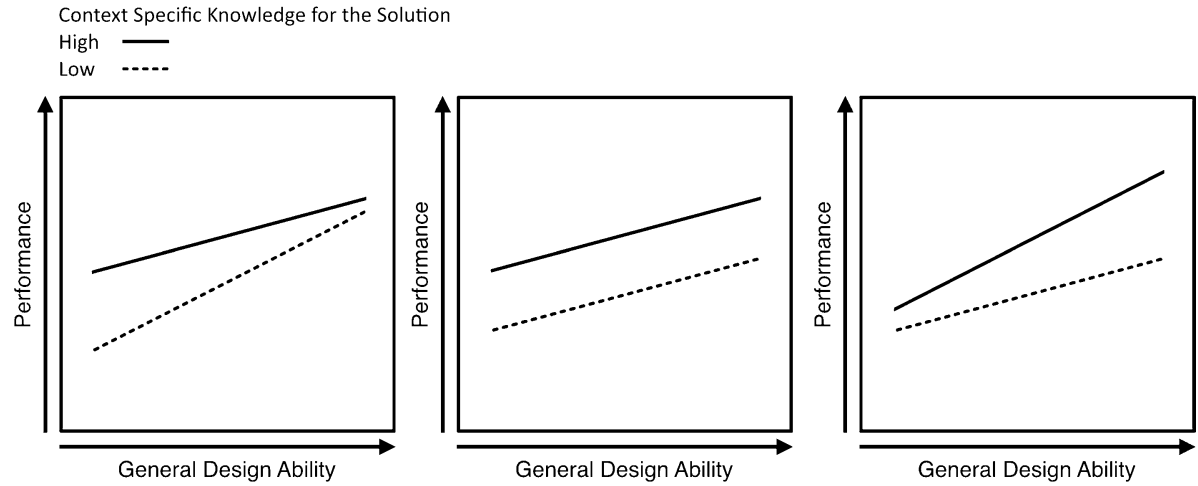

Fig. 2 Three hypotheses related to general design ability based on those described by Hambrick et al. (2016); the circumvention-of-limits hypothesis (left), the building blocks hypothesis (middle), and the richget-richer hypothesis (right)

Therefore, based on this research, an assumption can be made that having more knowledge for the solution is advantageous for learning or performance in a design task. However, this too should be critically considered with respect to fixation (Jansson and Smith 1991) and viewpoints of creativity as emerging through the absence of knowledge (Sweller et al. 2011). Based on this assumption, the hypotheses described by Hambrick et al. (2016) relating to the circumvention-of-limits can be examined relative to design (Fig. 2). Experimentally comparing groups of student's performance in design tasks would allow for the relevance of a general design ability to be determined by testing these hypotheses, however cognisance would need to be given to task related biases such as the context effect (Kimbell et al. 2004).

Importantly, in this line of inquiry, it should be noted that relative to general cognitive ability, “a high level of domain knowledge doesn't guarantee circumvention of limits associated with basic abilities. Basic abilities matter for novice performance, and sometimes they matter for expert performance" (Hambrick and Meinz 2011, p. 278) and the results of Hambrick et al. (2018) suggest that cognitive ability may impose limits that cannot be overcome through training. Therefore, in examining general design ability it is important to acknowledge the potential limitations of formal design education for developing design related competencies.

Finally, further theories and evidence may merit acknowledgment such as expectancy-value theory (Eccles 1983) mediating the actions of students and value systems of assessors, and the potential for personality factors such as emotional regulation (e.g., Grabner et al. 2007) and susceptibility to performance anxiety to impede performance (Hambrick et al. 2016). This paper does not aim or claim to be exhaustive in terms of providing evidence for framing the construct of a general design ability in terms of general secondary education. Rather, it aims to synthesise a body of evidence associated with cognitive psychology and learning with the aim of provoking further critique in a systematic fashion. In doing so, corroborating and opposing evidence would be welcomed, as would corroborating and opposing empirically supported, theoretical, and philosophical debate which progresses this agenda. 
Acknowledgements Open access funding provided by Royal Institute of Technology.

Open Access This article is licensed under a Creative Commons Attribution 4.0 International License, which permits use, sharing, adaptation, distribution and reproduction in any medium or format, as long as you give appropriate credit to the original author(s) and the source, provide a link to the Creative Commons licence, and indicate if changes were made. The images or other third party material in this article are included in the article's Creative Commons licence, unless indicated otherwise in a credit line to the material. If material is not included in the article's Creative Commons licence and your intended use is not permitted by statutory regulation or exceeds the permitted use, you will need to obtain permission directly from the copyright holder. To view a copy of this licence, visit http://creativecommons.org/licenses/by/4.0/.

\section{References}

Alavi, M., \& Leidner, D. (2001). Review: Knowledge management and knowledge management systems: Conceptual foundations and research issues. MIS Quarterly, 25(1), 107-136.

Anderson, J. (1983). The architect of cognition. Cambridge: Harvard University Press.

Ankiewicz, P., \& De Swardt, E. (2006). Some implications of the philosophy of technology for Science, Technology and Society (STS) studies. International Journal of Technology and Design Education, 16(2), 117-141.

Atkinson, S. (2017). So what went wrong and why? In E. Norman \& K. Baynes (Eds.), Design epistemology and curriculum planning (pp. 13-17). Loughborough: Loughborough Design Press.

Barlex, D. (2007). Assessing capability in design and technology: The case for a minimally invasive approach. Design and Technology Education: An International Journal, 12(2), 49-56.

Barlex, D. (2019). Too much D not enough T? [Blog post]. David and Torben for D\&T. https://dandt fordandt.wordpress.com/2019/07/06/too-much-d-not-enough-t/.

Barlex, D., \& Steeg, T. (2017). Re-building design \& technology in the secondary school curriculum version 2: A working paper. D\&TforD\&T.

Barlex, D., \& Trebell, D. (2008). Design-without-make: Challenging the conventional approach to teaching and learning in a design and technology classroom. International Journal of Technology and Design Education, 18(2), 119-138.

Bartholomew, S., Nadelson, L., Goodridge, W., \& Reeve, E. (2018a). Adaptive comparative judgment as a tool for assessing open-ended design problems and model eliciting activities. Educational Assessment. https://doi.org/10.1080/10627197.2018.1444986.

Bartholomew, S., Strimel, G., \& Jackson, A. (2018b). A comparison of traditional and adaptive comparative judgment assessment techniques for freshmen engineering design projects. International Journal of Engineering Education, 34(1), 20-33.

Bartholomew, S., Strimel, G., \& Yoshikawa, E. (2018c). Using adaptive comparative judgment for student formative feedback and learning during a middle school design project. International Journal of Technology and Design Education. https://doi.org/10.1007/s10798-018-9442-7.

Bartholomew, S., \& Yoshikawa-Ruesch, E. (2018). A systematic review of research around adaptive comparative judgement (ACJ) in K-16 education. In J. Wells (Ed.), CTETE-research monograph series (Vol. 1, Issue 1, pp. 6-28). Council on Technology and Engineering Teacher Education.

Biggs, J. (1996). Enhancing teaching through constructive alignment. Higher Education, 32(3), 347-364.

Bransford, J., \& Schwartz, D. (1999). Rethinking transfer: A simple proposal with multiple implications. Review of Research in Education, 24(1), 61-100.

Buckley, J., Seery, N., Power, J., \& Phelan, J. (2019). The importance of supporting technological knowledge in post-primary education: A cohort study. Research in Science \& Technological Education, 37(1), 36-53.

Bussey, T., Orgill, M., \& Crippen, K. (2013). Variation theory: A theory of learning and a useful theoretical framework for chemical education research. Chemistry Education Research and Practice, 14(1), 9-22.

Canty, D., Seery, N., \& Phelan, P. (2012). Democratic consensus on student defined assessment criteria as a catalyst for learning in technology teacher education. In T. Ginner, J. Hallström, \& M. Hultén (Eds.), PATT2012: Technology education in the 21st century (pp. 119-125). PATT.

Carpenter, T., Franke, M., Jacobs, V., Fennema, E., \& Empson, S. (2006). A longitudinal study of invention and understanding in children's multidigit addition and subtraction. Journal for Research in Mathematics Education, 29(1), 3-20. 
Chi, M., Roscoe, R., Slotta, J., Roy, M., \& Chase, C. (2012). Misconceived causal explanations for emergent processes. Cognitive Science, 36(1), 1-61.

Collins, H. (2010). Tacit and explicit knowledge. Chicago: University of Chicago Press.

Cropley, D., \& Cropley, A. (2010). Recognizing and fostering creativity in technological design education. International Journal of Technology and Design Education, 20(3), 345-358.

Dakers, J. (Ed.). (2006). Defining technological literacy: Towards an epistemological framework. London: Palgrave McMillan.

DBE. (2013). National policy pertaining to the programme and promotion requirements of the national curriculum statement Grades $R$-12. Department of Basic Education.

De Corte, E. (2003). Transfer as the productive use of acquired knowledge, skills, and motivations. Current Directions in Psychological Science, 12(4), 142-146.

DfE. (2013a). Design and technology programmes of study: Key stage 3-National curriculum in England. Department for Education.

DfE. (2013b). Design and technology programmes of study: Key stages 1 and 2-National curriculum in England. Department for Education.

Eccles, J. (1983). Expectancies, values and academic behaviors. In J. S. Pence (Ed.), Achievement and achievement motives: Psychological and sociological approaches (pp. 75-146). New York: W.H. Freeman.

Ericsson, A., \& Pool, R. (2016). Peak; Secrets from the new science of expertise. Houghton: Mifflin Harcourt.

Fitts, P., \& Posner, M. (1967). Human performance. Belmont: Brooks/Cole Publishing Company.

Geary, D. (1995). Reflections of evolution and culture in children's cognition: Implications for mathematical development and instruction. American Psychologist, 50(1), 24-37.

Geary, D. (2007). Educating the evolved mind: Conceptual foundations for an evolutionary educational psychology. In J. Carlson \& J. Levin (Eds.), Educating the evolved mind: Conceptual foundations for an evolutionary educational psychology (pp. 1-100). Charlotte: Information Age Publishing.

Geary, D. (2008). An evolutionarily informed education science. Educational Psychologist, 43(4), 179-195.

Gibson, K. (2008). Technology and technological knowledge: A challenge for school curricula. Teachers and Teaching, 14(1), 3-15.

Goldwater, M., \& Schalk, L. (2016). Relational categories as a bridge between cognitive and educational research. Psychological Bulletin, 142(7), 729-757.

Gorman, M. (2002). Types of knowledge and their roles in technology transfer. Journal of Technology Transfer, 27(3), 219-231.

Government of Malta. (2015). Directorate for learning and assessment programmes. https://curriculum.gov. $\mathrm{mt} / \mathrm{en} /$ Pages/Home.aspx.

Grabner, R., Stern, E., \& Neubauer, A. (2007). Individual differences in chess expertise: A psychometric investigation. Acta Psychologica, 124(3), 398-420.

Hallström, J., \& Ankiewicz, P. (2019). Laying down the "T" and "E" in STEM education: Design as the basis of an integrated STEM philosophy. In S. Pulé \& M. de Vries (Eds.), PATT2019: Developing a knowledge economy through technology and engineering education (pp. 187-194). Msida: Department of Technology and Entrepreneurship Education, University of Malta.

Hambrick, D., Altmann, E., \& Burgoyne, A. (2018). A knowledge activation approach to testing the circumvention-of-limits hypothesis. American Journal of Psychology, 131(3), 307-321.

Hambrick, D., Libarkin, J., Petcovic, H., Baker, K., Elkins, J., Callahan, C., et al. (2012). A test of the circumvention-of-limits hypothesis in scientific problem solving: The case of geological bedrock mapping. Journal of Experimental Psychology: General, 141(3), 397-403.

Hambrick, D., Macnamara, B., Campitelli, G., Ullén, F., \& Mosing, M. (2016). Beyond born versus made: A new look at expertise. In B. Ross (Ed.), Psychology of learning and motivation-Advances in research and theory (Vol. 64, pp. 1-55). Amsterdam: Elsevier Ltd. https://doi.org/10.1016/bs.plm.201

Hambrick, D., \& Meinz, E. (2011). Limits on the predictive power of domain-specific experience and knowledge in skilled performance. Current Directions in Psychological Science, 20(5), 275-279.

Hmelo-Silver, C., Duncan, R., \& Chinn, C. (2007). Scaffolding and achievement in problem-based and inquiry learning: A response to Kirschner, Sweller, and Clark (2006). Educational Psychologist, 42(2), 99-107.

Huang, S. L., \& Yang, C. W. (2009). Designing a semantic bliki system to support different types of knowledge and adaptive learning. Computers and Education, 53(3), 701-712.

Ingerman, A., \& Collier-Reed, B. (2011). Technological literacy reconsidered: A model for enactment. International Journal of Technology and Design Education, 21(2), 137-148.

Jacobson, M., Kapur, M., So, H.-J., \& Lee, J. (2011). The ontologies of complexity and learning about complex systems. Instructional Science, 39(5), 763-783. 
Jansson, D., \& Smith, S. (1991). Design fixation. Design Studies, 12(1), 3-11.

Jones, A., Buntting, C., \& de Vries, M. (2013). The developing field of technology education: A review to look forward. International Journal of Technology and Design Education, 23(2), 191-212.

Jones, I., \& Alcock, L. (2014). Peer assessment without assessment criteria. Studies in Higher Education, 39(10), 1774-1787.

Jones, I., Swan, M., \& Pollitt, A. (2015). Assessing mathematical problem solving using comparative judgement. International Journal of Science and Mathematics Education, 13(1), 151-177.

Kimbell, R. (2011). Wrong ... but right enough. Design and Technology Education: An International Journal, 16(2), 6-7.

Kimbell, R. (2012). Evolving project e-scape for national assessment. International Journal of Technology and Design Education, 22(2), 135-155.

Kimbell, R., \& Stables, K. (2007). Researching design learning: Issues and findings from two decades or research and development. Dordrecht: Springer.

Kimbell, R., Wheeler, T., Miller, S., Bain, J., Wright, R., \& Stables, K. (2004). Assessing design innovation: Final report. Goldsmiths, University of London.

Kirschner, P., Sweller, J., \& Clark, R. (2006). Why minimal guidance during instruction does not work: An analysis of the failure of constructivist, discovery, problem-based, experiential, and inquirybased teaching. Educational Psychologist, 41(2), 75-86.

Koedinger, K., \& Roll, I. (2012). Learning to think: Cognitive mechanisms of knowledge transfer. In K. Holyoak \& R. Morrison (Eds.), The Oxford handbook of thinking and reasoning (pp. 789-806). Oxford: Oxford University Press.

Kuhn, D. (2007). Is direct instruction an answer to the right question? Educational Psychologist, 42(2), 109-113.

Lawlor, K. B., \& Hornyak, M. (2012). SMART goals: How the application of SMART goals can contribute to achievement of student learning. Developments in Business Simulation and Experiential Learning, 39(1), 259-267.

Marton, F., \& Tsui, A. (2004). Classroom discourse and the space of learning. Abingdon: Routledge.

McCormick, R. (1997). Conceptual and procedural knowledge. International Journal of Technology and Design Education, 7(1-2), 141-159.

Mitcham, C. (1994). Thinking through technology: The path between engineering and philosophy. Chicago: Chicago University Press.

NCCA. (1983). Leaving certificate engineering syllabus. London: The Stationery Office, Department of Education and Science.

NCCA. (1984). Leaving certificate construction studies syllabus. London: The Stationery Office, Department of Education and Science.

NCCA. (2007a). Leaving certificate design and communication graphics syllabus. London: The Stationery Office, Department of Education and Science.

NCCA. (2007b). Leaving certificate technology syllabus. London: The Stationery Office, Department of Education and Science.

NCCA. (2018a). Junior cycle applied technology. London: Department of Education and Skills.

NCCA. (2018b). Junior cycle engineering. London: Department of Education and Skills.

NCCA. (2018c). Junior cycle wood technology. London: Department of Education and Skills.

NCCA. (2019). Junior cycle graphics. London: Department of Education and Skills.

Newell, A., \& Simon, H. (1972). Human problem solving. Upper Saddle River: Prentice-Hall.

Newman, G. (2017). How we know, what we should know: The building blocks of cultural awareness in design education. In E. Norman \& K. Baynes (Eds.), Design epistemology and curriculum planning (pp. 28-31). Loughborough: Loughborough Design Press.

Norman, E., \& Baynes, K. (Eds.). (2017). Design epistemology and curriculum planning. Loughborough: Loughborough Design Press.

Orgill, M. (2012). Variation theory. In N. Seel (Ed.), Encyclopedia of the sciences of learning (pp. 3391-3393). Berlin: Springer.

Ormrod, J. (2014). Human learning, Vol. 7. London: Pearson.

Pirttimaa, M., Husu, J., \& Metsärinne, M. (2017). Uncovering procedural knowledge in craft, design, and technology education: A case of hands-on activities in electronics. International Journal of Technology and Design Education, 27(2), 215-231.

Polanyi, M. (1969). Knowing and being: Essays. Chicago: Chicago University Press.

Pool, J., Reitsma, G., \& Mentz, E. (2013). An evaluation of Technology teacher training in South Africa: Shortcomings and recommendations. International Journal of Technology and Design Education, $23(2), 455-472$. 
Rauscher, W. (2011). The technological knowledge used by technology education students in capability tasks. International Journal of Technology and Design Education, 21(3), 291-305.

Rittle-Johnson, B., Star, J., \& Durkin, K. (2009). The importance of prior knowledge when comparing examples: Influences on conceptual and procedural knowledge of equation solving. Journal of Educational Psychology, 101(4), 836-852.

Rossouw, A., Hacker, M., \& de Vries, M. (2011). Concepts and contexts in engineering and technology education: An international and interdisciplinary Delphi study. International Journal of Technology and Design Education, 21(4), 409-424.

Runesson, U. (2005). Beyond discourse and interaction. Variation: A critical aspect for teaching and learning mathematics. Cambridge Journal of Education, 35(1), 69-87.

Runesson, U. (2006). What is it possible to learn? On variation as a necessary condition for learning. Scandinavian Journal of Educational Research, 50(4), 397-410.

Ryle, G. (1949). The concept of the mind. Chicago: University of Chicago Press.

Sadler, D. R. (2009). Transforming holistic assessment and grading into a vehicle for complex learning. In G. Joughin (Ed.), Assessment, learning and judgement in higher education (pp. 45-63). Berlin: Springer.

Salthouse, T. (1991). Expertise as the circumvention of human processing limitations. In K. A. Ericsson \& J. Smith (Eds.), Toward a general theory of expertise: Prospects and limits (pp. 286-300). Cambridge: Cambridge University Press.

Schmidt, H., Loyens, S., van Gog, T., \& Paas, F. (2007). Problem-based learning is compatible with human cognitive architecture: Commentary on Kirschner, Sweller, and Clark (2006). Educational Psychologist, 42(2), 91-97.

Scottish CCC. (1996). Technology education in Scottish schools: A statement of position. Scottish Consultative Council of the Curriculum.

Seery, N. (2017). Modelling as a form of critique. In P. J. Williams \& K. Stables (Eds.), Critique in design and technology education (pp. 255-273). Berlin: Springer.

Seery, N., Buckley, J., Delahunty, T., \& Canty, D. (2019). Integrating learners into the assessment process using adaptive comparative judgement with an ipsative approach to identifying competence based gains relative to student ability levels. International Journal of Technology and Design Education, 29(4), 701-715.

Seery, N., Canty, D., \& Phelan, P. (2012). The validity and value of peer assessment using adaptive comparative judgement in design driven practical education. International Journal of Technology and Design Education, 22(2), 205-226.

Seery, N., Kimbell, R., Buckley, J., \& Phelan, J. (2019). Considering the relationship between research and practice in technology education: A perspective on future research endeavours. Design and Technology Education: An International Journal, 24(2), 1-12.

Shaw, K. (2002). Education and technological capability building in the Gulf. International Journal of Technology and Design Education, 12(1), 77-91.

Skolverket., (2018). Curriculum for the compulsory school, preschool class and school-age educare: Revised 2018. Stockholm: Skolverket.

Spender, J.-C. (1993). Competitive advantage from tactit knowledge? Unpacking the concept and its strategic implications. Academy of Management Proceedings, 1883(1), 37-41.

Spendlove, D. (2017). Design thinking: What is it and where might it reside? In E. Norman \& K. Baynes (Eds.), Design epistemology and curriculum planning (pp. 39-42). Loughborough: Loughborough Design Press.

Stables, K. (2008). Designing matters; Designing minds: The importance of nurturing the designerly in young people. Design and Technology Education: An International Journal, 13(3), 8-18.

Steedle, J. T., \& Ferrara, S. (2016). Evaluating comparative judgment as an approach to essay scoring. Applied Measurement in Education, 29(3), 211-223.

Surowiecki, J. (2004). The wisdom of crowds: Why the many are smarter than the few and how collective wisdom shapes business, economies, societies, and nations. New York: Doubleday \& Co.

Sweller, J. (1988). Cognitive load during problem solving: Effects on learning. Cognitive Science, 12(2), $257-285$.

Sweller, J. (2008). Instructional implications of David C. Geary's evolutionary educational psychology. Educational Psychologist, 43(4), 214-216.

Sweller, J., Ayres, P., \& Kalyuga, S. (2011). Cognitive load theory. Berlin: Springer.

Sweller, J., Kirschner, P., \& Clark, R. (2007). Why minimally guided teaching techniques do not work: A reply to commentaries. Educational Psychologist, 42(2), 115-121.

Thurstone, L. L. (1927). A law of comparative judgement. Psychological Review, 34(4), 273-286. 
Williams, P. J. (2009). Technological literacy: A multliteracies approach for democracy. International Journal of Technology and Design Education, 19(3), 237-254.

Williams, P. J., \& Kimbell, R. (2012). Special issue on e-scape [Special issue]. International Journal of Technology and Design Education, 22(2), 123-270.

Zimmerman, B. (2000). Self-efficacy: An essential motive to learn. Contemporary Educational Psychology, 25(1), 82-91.

Publisher's Note Springer Nature remains neutral with regard to jurisdictional claims in published maps and institutional affiliations. 